\title{
Acute myocardial infarction caused by paradoxical tumorous embolism as a manifestation of hepatocarcinoma
}

\author{
O Diaz Castro, H Bueno, L A Nebreda
}

Heart 2004;90:e29 (http://www.heartjnl.com/cgi/content/full/90/5/e29). doi: 10.1136/hrt.2004.033480

\begin{abstract}
A 71 year old patient presented with a non-ST segment elevation acute myocardial infarction. The echocardiogram showed several masses attached to the interatrial septum. Several days after admission the patient died. A postmortem examination found a large hepatocarcinoma with intravascular and intracardiac metastases and several myocardial infarctions of different ages. The infarctions had been caused by coronary paradoxical embolisms through a patent foramen ovale and contained neoplastic cells from the liver carcinoma, which had not been diagnosed. The cause of death was a massive pulmonary embolism.
\end{abstract}

A 71 year old man was admitted to the emergency department with typical oppressive chest pain accompanied by profuse sweating and mild dyspnoea lasting for three hours at the time of admission. The patient had a previous diagnosis of chronic $\mathrm{C}$ type hepatitis, porphyria, and mild chronic obstructive lung disease. The ECG showed block of the anterior division of the left bundle branch and $0.5 \mathrm{mV}$ ST segment elevation in the right precordial leads. The patient was admitted to the coronary care unit and treated with nitrates, aspirin, diltiazem, and enoxaparin, becoming asymptomatic. The laboratory tests showed a rise and fall of the cardiac markers with a peak creatine kinase MB concentration of $40 \mathrm{ng} / \mathrm{ml}$.

On the third day a transthoracic echocardiogram showed a large mass in the right atrium arising from the inferior vena cava that was partially occupied. No abnormalities in global or segmental contractility in the left or the right ventricles were found. Transoesophageal echocardiography showed a large $6 \times 3 \mathrm{~cm}$ mass placed against the interatrial septum (fig lA). The Doppler study showed a patent foramen ovale. Laboratory analyses showed a major increase of biochemical tumour markers, particularly $\alpha$ fetoprotein (more than $2500 \mathrm{ng} / \mathrm{ml})$.

The day after the transoesophageal echocardiogram was recorded, the patient presented with a sudden pleuritic chest pain, with severe dyspnoea and refractory hypoxaemia and cyanosis. Pulmonary arteriography was urgently performed, showing obstruction of the main right and left pulmonary arteries. Intra-arterial thrombolysis with urokinase was administered with no clinical or haemodynamic improvement. The patient died four hours later. The pathological findings showed several yellowish $2 \mathrm{~cm}$ diameter nodules in the liver. One of the masses had invaded the suprahepatic veins and the inferior vena cava (fig $\mathrm{lC}$ ). Several masses were attached to the inferior vena cava and right atrial wall (fig 1B), as well as to a dilated right ventricle, main pulmonary arteries, and their distal branches. A 7-8 mm diameter patent foramen ovale was also found. Histological analysis of the hepatic masses showed neoplastic cells with an eosinophilic cytoplasm and areas of focal necrosis. The same type of neoplastic cells were found in intravascular and intracardiac masses. The epicardial coronary arteries had no signs of atherosclerotic obstructions but had several microscopic embolisms in the distal branches of the circumflex and anterior descending coronary arteries formed by groups of the same tumorous cells (fig lD). The myocardium had nontransmural infarctions that had occurred over different periods of time surrounding the obstructed coronary arteries.

\section{DISCUSSION}

This case has the distinction of comprising three rare entities: intracavitary metastases, paradoxical coronary tumorous embolisation through a patent foramen ovale, and acute myocardial infarction as the first clinical manifestation of a hepatic carcinoma.

Cardiac metastases are 20-40 times more common than primary cardiac tumours at necropsy. ${ }^{1}$ The most common metastatic tumours of the heart are carcinomas of the lung and breast because of their prevalence. Nevertheless, melanoma is the tumour with the greatest propensity to metastasise to the heart and pericardium. ${ }^{1}$

Echocardiography is the diagnostic method of choice. ${ }^{2}$ In some studies with transoesophageal echocardiography, secondary malignant tumours in the right atrium usually came from the inferior vena cava and were mostly hypernephromas, Wilms tumour, hepatomas, and chondrosarcoma or uterine leiomyomatosis. ${ }^{2}{ }^{3}$ Intracavitary metastases in the right atrium have also been reported in patients with testicular carcinoma, ovarian carcinoma, lymphoma, Ewing sarcoma, and adenocarcinoma of the colon. ${ }^{4}$

Myocardial infarction is rarely caused by a coronary embolism reported in the setting of a variety of clinical situations such as endocarditis, postcardiac or coronary interventional procedures, or calcified aortic stenosis. ${ }^{5-8}$ Coronary embolism with a tumorous origin is very rare (one of 61 cases in a series ${ }^{6}$ ) and it usually appears in the medical literature as case reports. ${ }^{9}{ }^{10}$ Most often the embolism comes from left sided tumours such as myxomas or fibroelastomas. Embolism from the right side almost always implies the existence of a patent foramen ovale, and this is more common when the patient has high right side pressures caused by previous pulmonary embolism, as in this case. Extracardiac tumours that have been described as embolising into the coronary arteries include choriocarcinoma of the uterus, anaplastic small cell carcinoma of the lung, malignant fibrous histiocytoma, and melanoma. ${ }^{10-12}$ To our knowledge this is the first case report of paradoxical coronary emboli caused by a liver carcinoma.

\section{ACKNOWLEDGEMENTS}

Thanks to the Pathology Department of Gregorio Marañon General Hospital for their help in preparing the images.

\section{Authors' affiliations}

O Diaz Castro, H Bueno, Cardiology Department, Hospital General Universitario "Gregorio Marañón", Madrid, Spain 

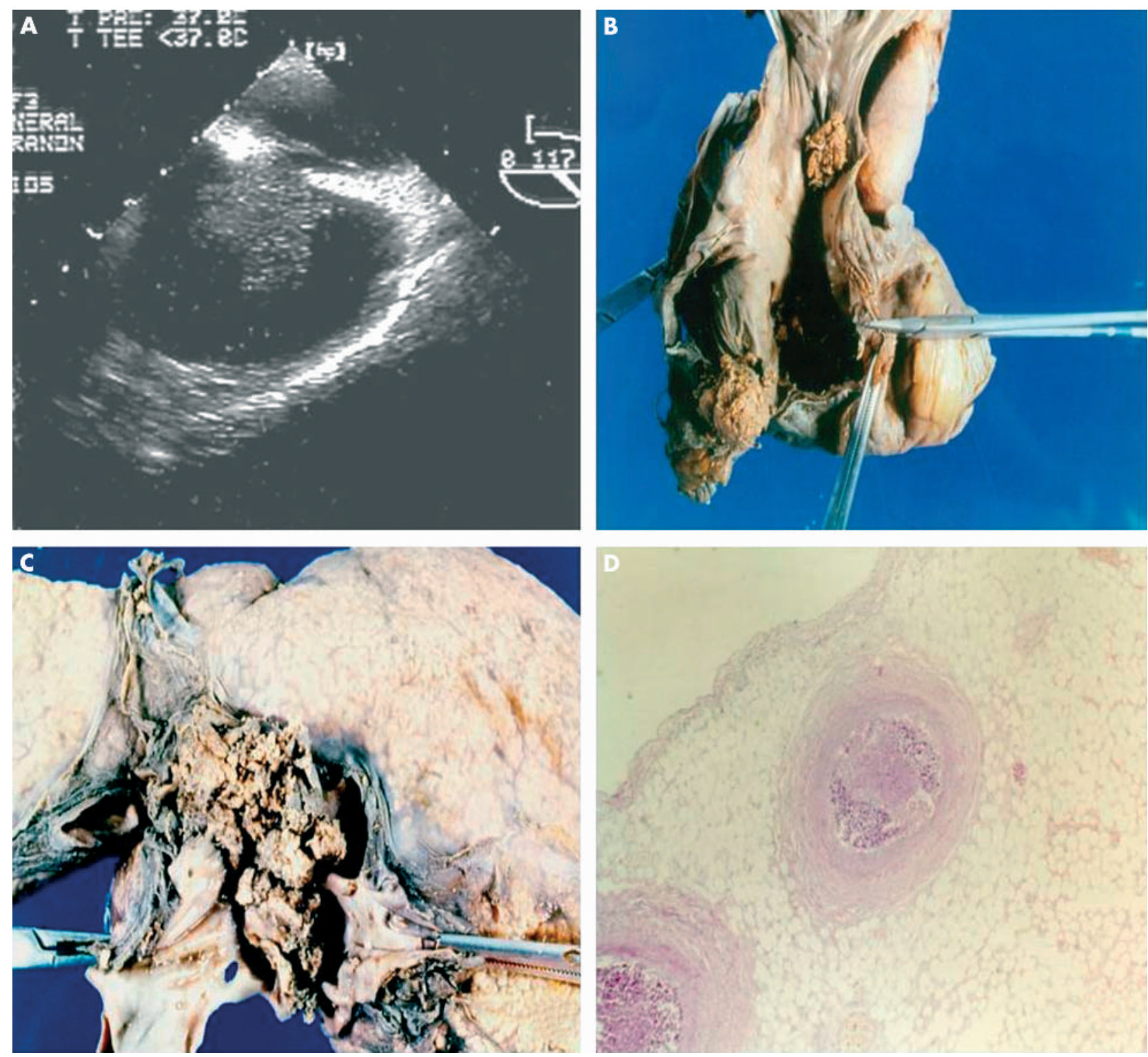

Figure 1 (A) Transoesophageal view of the right atrium with a mass attached to the interatrial septum. (B) Macroscopic view of several masses in the heart. (C) Macroscopic view of the liver and inferior vena cava infiltrated by the tumour. (D) Coronary branch occupied by neoplastic cells.

L A Nebreda, Geriatrics Department, Hospital General Universitario "Gregorio Marañón"

Correspondence to: Dr O Diaz Castro, Cardiology Department, $5^{\mathrm{a}}$ planta Centro, Hospital do Meixoeiro, Aptdo oficial sin numerar, 36200 Vigo, Pontevedra, Spain; odiazcastro@hotmail.com

Accepted 26 January 2004

\section{REFERENCES}

1 Endo A, Ohtahara A, Kinugawa T, et al. Characteristics of 161 patients with cardiac tumors diagnosed during 1993 and 1994 in Japan. Am J Cardiol 1997;79:1708-11.

2 Errichetti AM, Weyman AE. Cardiac tumors and masses. In: Weyman AE, ed Principles and practice of echocardiography. Philadelphia: Lea \& Ferbiger, 1994: 1135

3 Lynch M, Clements SD, Shanewise JS, et al. Right-sided cardiac tumors detected by transesophageal echocardiography and its usefulness in differentiating the benign from the malignant ones. Am J Cardiol 1997;79:781-4.

4 Loire R, Tabib A. [Coronary embolism: apropos of 61 anatomo-clinical cases] Arch Mal Coeur Vaiss 1985;78:821-7.
5 Herzog CA, Henry TD, Zimmer SD. Bacterial endocarditis presenting as acute myocardial infarction: a cautionary note for the era of reperfusion. Am J Med 1991;90:392-7.

6 Saber RS, Edwards WD, Bailey KR, et al. Coronary embolization after balloon angioplasty or thrombolytic therapy: an autopsy study of 32 cases. J Am Coll Cardiol 1993;22:1283-8.

7 Salka S, Almassi GH, Leitschuh ML, et al. Spontaneous coronary artery embolus associated with calcific aortic stenosis. Chest 1994:105:1289-90.

8 Cina SJ, Raso DS, Crymes LW, et al. Fatal suture embolism to the left anterior descending coronary artery: a case report and review of the literature. Am J Forensic Med Pathol 1994;15:142-5.

9 Grote J, Mügge A, Schfers HJ, et al. Multiplane transesophageal echocardiography detection of a papillary fibroelastoma of the aortic valve causing myocardial infarction. Eur Heart J 1995;16:426-9.

10 Ackermann DM, Hyma BA, Edwards WD. Malignant neoplastic emboli to the coronary arteries: report of two cases and review of the literature. Hum Pathol 1987; 18:955-9.

11 Vasiljevic JD, Abdulla AK. Coronary embolism by metastatic choriocarcinoma of the uterus: an unusual cause of ischemic heart disease. Gynecol Oncol 1990; 38:289-92.

12 Culver RA, Bampton PA, Bignold LP. Aortic and coronary embolism of anaplastic small-cell carcinoma of the lung. Med J Aust 1987; 147:455-6. 